\title{
Impact of Service Quality of House Wedding Events on the Service Value and Satisfaction
}

\author{
Soungyeon $\mathrm{Kim}^{1}$, Mihye Lee ${ }^{2}$ \\ ${ }^{1,2}$ Graduate School of Event and Convention Management, Kyonggi University, Seoul, Republic of \\ Korea
}

\begin{abstract}
With the current popularity of the newly emerged house wedding events (HWE), this study aims to investigate the impact of service quality of house wedding events on service value and satisfaction of customers. Based on literature review, two main components of HWE service quality attributes were selected: physical service and human service. For service value, three components were chosen: social, aesthetic, and monetary value. The study conducted self-administered questionnaire survey from July $1^{\text {st }}$ to August $31^{\text {st }} 2013$ targeting 300 male and female over age 20 with experiences of participating in HWE held in Seoul metropolitan areas. The final valid samples were 267 copies. Frequency analysis, exploratory factor analysis, reliability analysis and regression analysis were conducted on the collected data. The result of this study showed a significant positive impact of HWE's service quality, which in turn influence satisfaction. In addition, the study found the direct impact of HWE's service quality on customer satisfaction. Based on the results, this study also discussed practical implications.
\end{abstract}

\section{Introduction}

With economic development and socio-cultural influence, weddings in Korea have shifted from the routine and formal moods of the conventional wedding culture. The house wedding event which emerged as a part of these events is an event where the bride and groom host a party in a small and middle sized party hall or open garden inviting their family members and friends to feel happiness and joy with heartfelt congratulations. House wedding events are different from the conventional wedding ceremonies in that they set characteristic and differentiated themes and concepts, construct stories that match the theme to allow the bride and groom to enjoy the event with the guests together. With more diversification of wedding style and places to enjoy the new wedding culture, many people these days prefer the house wedding event and want to choose the event by themselves.

Along with the growth of house wedding event market, people increasingly became to pursue special meaning and value for their own wedding, and this has come to emphasize importance of service values focusing on the service quality of the house wedding event. Service should be provided with superior quality to enhance the level of the service value and subsequently it can extend positive influence on satisfaction and future behavioral intention [1]. Consequently, the importance of the wedding service and intense competition is increasingly growing among many companies actively trying to meet the changes in customers' wedding preferences.

With growth of today's house wedding event industry, it is necessary to approach the market 
academically and seek the ways for managing and improving the service quality, however, there has been few studies dealing with the issue. Therefore, in order to explore developmental strategies of house wedding events, which has newly emerged to meet the needs of the diversifying society and has attracted attention recently, this study aims to investigate the impact of the service quality of house wedding events on service value and satisfaction perceived by participants.

\section{Background}

\subsection{House Wedding Event Service Quality}

A house wedding event has the merit of being able to hold a small wedding ceremony by inviting family members and close friends in a comfortable atmosphere. It is a format that the bride couple and the guests can celebrate the wedding privately. It is one of the most fascinated wedding events for brides and grooms these days as it organizes a programmed event with a theme and story in a small or middle sized space which can customize the bride and groom's taste or style.

Getz [2] defines an event as a function comprised of unique mixture of temporal period, setting, management and the people. Goldblatt [3] refers event as the moment where a ritual process satisfying a certain need is happening. Shone and Parry [4] observes that an event includes non-routine activities being held with social, cultural and organizational purposes which can be distinguished from the routine activities. With development of a society, the role and impact of events are expanding to various fields such as socio-cultural fields, corporation and wedding [5] .

Parasuraman et al.[6] defined service quality as the difference between the expectation before provision of the service and the actual service perceived by the customers. Baker and Crompton [7] states that service quality is assessment of service attributes mostly controlled by the service provider and the measurement based on the outcome of the assessment. Lovelock and Gummesson [8] also defined service quality as matching or exceeding the customers' expectation or the expected level. Meanwhile, based on the five service quality dimensions of Parasuraman et al.[6], Wakefield and Blodgett [9], Cronin and Tailor [10], and Reimer and Kuehn [11] measured two dimensions of tangible and intangible elements in their studies.

This study defined house wedding event service quality as the assessment of participants on the tangible and intangible services of planned events or ceremonies performed through pre-planned programs by designing the ceremony of socially acknowledging the couple to live together with a certain concept and by letting people gather together under an artificially predetermined objective. The study constructed measurement tool as two factors of physical service (the environment such as facilities of house wedding events) and human service appearing through personal interaction in the service encounter.

\subsection{Service Value}

Service value is the trade-off between the service quality and the expense and time paying to get the service [12-13]. It is also viewed as a form of value that has close relations through the convenience consumers receive by paying the cost of efforts, time and monetary expense [14]. Service value is also referred as the advantage or benefit for the expectation born by the customer who used the products and services.

The definition of service value varies according to different viewpoints of the scholars. Chen and $\mathrm{Hu}[15]$ defined it as the assessment of transactional viewpoints which are received as the trade-off effect in the middle of perceived product quality and the price. The present study defined service value of house wedding events as the subjective assessment of participants for the trade-off between the tangible/ intangible quality, convenience and utility perceived by the participants in the process of a house wedding event and the convenience obtained contrary to the cost or compromise. In Zeithmal's 
[13] research, he constructed service value as economic value, aesthetic value and social value. Sweeney and Souter [16], Sanchez et al. [17] and Lee et al. [18] constructed it as emotional value, social value and functional value. Based on the previous studies, the present study constructed the service value as social value, aesthetic value and monetary value. Social value refers to the value oriented to the convenience of the wedding ceremony and the event toward the community beyond the private interest of the participants. Aesthetic value is the value determined by the subjective utility of the participants that can cause various kinds of emotions responding to the service quality. Monetary value is the value at the level of participants' subjective assessment through the comparison between the total price paid by the participants for the consumption behavior and the service quality of the provider.

\subsection{Satisfaction}

Caruana [19] defined satisfaction as the emotional responses with various intensity occurring after the customers' purchasing. Hellier et al. [20] defined the satisfaction as the overall joy or satisfaction felt by customers as the result of service performance to satisfy needs and expectations of customers. The present study defined satisfaction of participants about house wedding events as the outcome perceived before and after experiencing house wedding events. As most of the researchers formulated the measuring tool of mono-dimension, this study also constructed satisfaction into mono-dimensional 4 items.

\section{Method}

\subsection{Research Model and Hypothesis}

A house wedding event can be considered as a typical service product in the aspect that it provides food and beverage with various services including entertainment based on the human resource in a physical environment constructed for service delivery. The positive perception of the service quality of the physical environment and human service for providing these services leads to favorable value for the service provided and subsequently it leads to customers' satisfaction for the product. These findings were shown in numerous studies in relation to service quality. Especially studies by Bolton and Drew [21], Dodds et al. [22], Kerin et al. [23], Sureshchanndra et al. [24] and Ribbink et al. [25] found that service quality has significant impact on service value and this in turn can have significant impact on customer satisfaction.

In their studies on service quality and customer satisfaction, Parasuranman et al. [6] and Taylor and Baker [26] proved that higher level of service quality have more impact on enhancing customer satisfaction. Bitner [27] and Wakefield and Blodgett [28] also explained that physical service has significant impact on customer satisfaction. Service marketing research also found that while perception of service quality is a cognitive response for a service experience, customer satisfactions are mutually interrelated through emotional responses [29].

In their study, Bolton and Drew [21] found that service value has direct causal relation with customer satisfaction through the perception of justice appearing by comparison of gain and loss. Patterson and Spreng [30] and Parasuraman and Grewal [31] also suggested that service value is a preceding factor having impact on customer satisfaction.

Based on the findings from the previous studies on impact relations among service quality, service value and satisfaction, this study set hypotheses on impact relations among service quality, service value and satisfaction of house wedding events as follows:

H1. House wedding event service quality has positive impact on service value.

H2. House wedding event service quality has positive impact on satisfaction.

H3. House wedding event service value has positive impact on satisfaction. . 
The research model based on the hypotheses is shown in Figure 1.

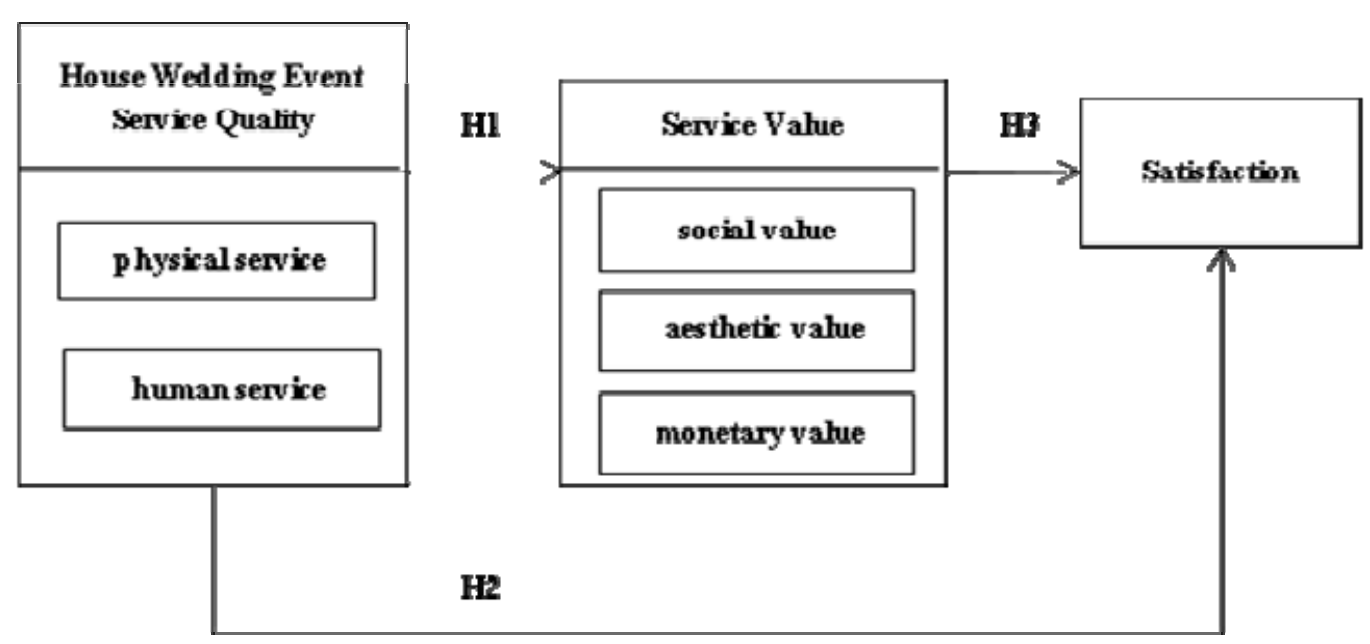

Figure 1. Research Model

\subsection{Questionnaire Designs and Data Collection}

For the list of study participants, we referred to house wedding professional planners' site promotion materials through the internet and finally chose the Seoul Metropolitan areas where the majority of house wedding events is held. The research targets were male and female over age 20 with experiences of participating in house wedding events as guests in the aforementioned areas. This survey was conducted from July $1^{\text {st }}$ to August $31^{\text {st }}$ 2013. Among total distributed 300 copies, excluding 33 copies which were not collected or were not answered sincerely, totally 267 copies $(89.0 \%)$ were determined as valid copies. Using statistical package software SPSS 20.0, frequency analysis, exploratory factor analysis, reliability analysis and regression analysis were conducted on the collected data.

Based on the studies of Cronin and Tailor [10], Bitner [27], Wakefield and Blodgett [9], and Brady and Cronin [32], the attributes of the house wedding event service quality were constructed with 2 factors of physical service and human service including 12 items(e.g. The accessibility to the location was convenient). Next, based on studies of Zeithmal [13], Sheth et al. [33], Mathwich et al. [34], Petrick [35], Sweeny and Souter [16], Sanchez et al. [17], and Lee et al. [18], service value was constructed into 16 items from 3 factors of social value, aesthetic value and monetary value (e.g. It was attractive). Lastly, based on studies of Westbrook and Oliver [36], Lounsbury and Polik [37], Oliver [38], 4 items on satisfaction were constructed (e.g. the proceeding and content of the event was satisfactory).

\section{Results}

\subsection{Validity and Reliability Tests}

The result of exploratory factor analysis and reliability test of house wedding event service quality showed that, with KMO value of 0.887 , Bartlett's test of sphericity was $1,136.006(\mathrm{p}=0.000)$, and 
eigenvalues of physical service and human service were 3.335 and 2.842 respectively. The total variance explanation power was $56.150 \%$ and with factor loadings of $0.537-0.789$ for each measured items, it showed to be an important variable. Cronbach's $\alpha$ value was overall 0.878 and it verified the suitability of items. Among the items on human service, an item stating 'The staff of the house wedding event actively dealt with customers to solve their complaints' was eliminated because it was difficult for the house wedding staff to provide one-to-one service to all customers.

In the case of service value, it showed that with KMO value of 0.886 , Bartlett's test of sphericity was $1,827.769(\mathrm{p}=0.000)$. Eigenvalues were drawn 3 factors of social value (3.335), aesthetic value (2.819) and monetary value (3.042). With total variance explanation power of $57.478 \%$ and factor loadings of 0.471-0.803 for each measured items, it showed to be an important variable. Cronbach's $\alpha$ value was overall 0.904 and the confidence level was high.

In the case of satisfaction, it showed that with KMO value of 0.823 , Bartlett's test of sphericity was $451.604(\mathrm{p}=0.000)$. With eigenvalue of 2.790 and total variance explanation power of $69.7561 \%$, it showed sufficient explanation power. Factor loadings for each measured items were $0.820-0.848$ and it showed to be an important variable. Cronbach's $\alpha$ was 0.855 to be highly verified

\subsection{Testing of Hypotheses}

The results of testing the hypotheses of the study are shown in Table 1. The result shows that service quality, service value and satisfaction all had high explanation power among the regression model and positive impact among the variables. All the hypotheses were supported.

Table 1. Results of Testing Hypotheses

\begin{tabular}{|c|c|c|c|c|c|c|c|c|}
\hline \multicolumn{2}{|c|}{ Hypotheses } & IV & DV & F value & $\mathrm{R}^{2}$ value & $\beta$ & $\mathrm{t}$-value & Result \\
\hline \multirow{6}{*}{$\mathrm{H} 1$} & \multirow{2}{*}{$1-1$} & Physical service & \multirow{2}{*}{ Social Value } & \multirow{2}{*}{98.499} & \multirow{2}{*}{0.427} & 0.315 & $5.195^{* *}$ & \multirow{2}{*}{ accepted } \\
\hline & & Human service & & & & 0.405 & $6.676^{* *}$ & \\
\hline & \multirow{2}{*}{$1-2$} & Physical service & \multirow{2}{*}{ Aesthetic Value } & \multirow{2}{*}{77.712} & \multirow{2}{*}{0.371} & 0.465 & $7.314 * *$ & \multirow{2}{*}{ accepted } \\
\hline & & Human service & & & & 0.195 & $3.062 *$ & \\
\hline & \multirow{2}{*}{$1-3$} & Physical service & \multirow{2}{*}{ Monetary Value } & \multirow{2}{*}{116.331} & \multirow{2}{*}{0.468} & 0.310 & $5.309 * *$ & \multirow{2}{*}{ accepted } \\
\hline & & Human service & & & & 0.443 & $7.574^{* *}$ & \\
\hline \multirow{2}{*}{\multicolumn{2}{|c|}{$\mathrm{H} 2$}} & Physical service & \multirow{2}{*}{ Satisfaction } & \multirow{2}{*}{105.110} & \multirow{2}{*}{0.443} & 0.296 & $4.946^{* *}$ & \multirow{2}{*}{ accepted } \\
\hline & & Human service & & & & 0.436 & $7.293 * *$ & \\
\hline \multirow{3}{*}{\multicolumn{2}{|c|}{$\mathrm{H} 3$}} & Social Value & \multirow{3}{*}{ Satisfaction } & \multirow{3}{*}{113.128} & \multirow{3}{*}{0.563} & 0.180 & $3.279 * *$ & \multirow{3}{*}{ accepted } \\
\hline & & Aesthetic Value & & & & 0.243 & $4.608^{* *}$ & \\
\hline & & Monetary Value & & & & 0.444 & $7.953 * *$ & \\
\hline
\end{tabular}

$(* \mathrm{p}<.01, * * \mathrm{p}<.001)$

\section{Conclusion}

This study investigated impact relations among service quality, service value and satisfaction of house wedding events which are gathering public attention these days. Based on the theoretical review and empirical research result, the study presents the following implications.

First, the hypotheses 1,2 and 3, which the study set based on the previous studies and drew 
assessment tools in order to empirically test impact relations among service quality, service value and satisfaction of house wedding events targeting the participants, showed to have positive impact among all variables. The finding of this study which proved that house wedding event service quality had positive impact on service value was consistent with findings of previous studies, showing the significance and value of this study.

Second, as the result of empirical research shows that both physical service and human service of house wedding event had positive impact on service value and satisfaction, it would be necessary to seek strategic plans that can improve physical and human service quality to meet the service value of house wedding event participants. This implies that continuous management of service quality can lead to boosting of house wedding events and can present differentiation from the conventional wedding events. It in turn will lead to the enhancement of service value and satisfaction of service quality of house wedding events.

Third, it would be also necessary for the house wedding planners to plan and prepare diversified wedding events in order to provide memorable moments of congratulations for the brides and grooms. As the house wedding events are customized events matching to the style of the bride and groom, it would be also necessary to create enjoyable atmosphere for the guests, plan wedding events programs that can exchange communication among the invited guests, and provide information to them actively.

There are also limitations in this study. First, it limited the variables. In other words, the study limited service quality of house wedding events to service value and satisfaction. Satisfaction is a variable that can identify the relational orientation of the future. However, it was not used in the study. Second, there were limitations in the geographical scope and subjects. It would be difficult to generalize the results found from participants of house wedding events in Seoul Metropolitan areas and during the period of July and August.

Therefore, in the future studies, it would be necessary to conduct research from various perspectives in order to sufficiently satisfy needs of customers, i.e. the hosts and guests of house wedding events, as the wedding culture is constantly changing. It is also necessary to conduct in-depth studies for not only the theoretical development but also the practical development.

\section{References}

1. C. F. Chen, TRPA, $42,133-147$ (2008)

2. D. Getz, Event Management \& Event Tourism. New York: Cognizant Communication Corporation (1997)

3. J. J. Goldblatt, The International Dictionary of Event Management, John Wiley \& Sons (2001)

4. A. Shone, B. Parry, Successful Events Management, London: Thomson (2004)

5. D. Getz, TM, 29, 3, 403-428 (2008)

6. A. Parasuraman, V. A. Zeithmal, L. L. Berry, JOR, 64, 1, 12-40 (1988)

7. D. Baker, J. Crompton, AOT, 27, 3, 785-804 (2000)

8. D. Lovelock, E. Gummesson, JOSR, 7, 1, 20-41 (2004)

9. K. L. Wakefield, J. G. Blodgett, PAM, 16, 1, 51-68 (1999)

10. J. J. Cronin, S. A. Taylor, JOM, 56, 3, 55-68 (1992)

11. A. Reimer, R. Kuhen, EJOM, 39, 7/8, 785-808 (2005)

12. M. B. Holbrook, K. P. Corfman, Perceived Quality: How Consumers View Stores and Merchandise, MA: Lexington Books (1985)

13. V. A. Zeithmal, JOM, 52,7, 2-22 (1988)

14. V. A. Zeithmal, M. J. Bitner, Service Marketing, New York: Mcgraw-Hill Book Company (1996)

15. P. T. Chen, H. H. Hu, IJOHM, 29, 405-412 (2010)

16. J. C. Sweeney, G. N. Soutar, JOR, 77, 2, 203-220 (2001)

17. J. Sanchez, L, Callarisa, R. M. Rodriguez, M. A. Moliner, TM, 27, 3, 394-409 (2006)

18. C. K. Lee, Y. S. Yoon, S. K. Lee, TM, 28, 1, 204-214 (2007)

19. A. Caruana, JOR, 66, 1,33-56 (2002) 
20. P. K. Hellier, G. M. Geursen, R. A. Carr, J. A. Richard, EJOM, .37, 11/12, 1762-800 (2003)

21. R. N. Bolton, J. H. Drew, JOCR, 17, 3, 375-384 (1991)

22. W. B. Dodds, K. B. Monroe, D. Grewal, AICR, 12, 85-90 (1991)

23. A. Kerin, R. A. Jain, D. J. Howard, JOR, 68, 4, 376-397 (1992)

24. G. S. Sureshchanndra, C. Rajendran, R. N. Anantharaman, JOSM, 16, 4, 363-379 (2003)

25. D. Ribbink, A. C. R. Van Riel, V. Liljander, S. Streukens, MSQ, 14, 446-456 (2004)

26. S. A. Taylor, T. L. Baker, JOR 70, 2, 163-178 (1994)

27. M. Bitner, JOM, 56, 2, 57-71 (1992)

28. K. L. Wakefield, J. G. Blodgett, JOSM,.8, 3, 66-76 (1994)

29. J. F. Petrick, JOTR, 42, 5, 397-407 (2004)

30. P. G. Patterson, R. A. Spreng, IJOSIM, 8, 5, 414-434 (1997)

31. A. Parasuraman, D. Grewal, JOAOMS, 28, 168-174 (2000)

32. J. Brady, K. Michael, Jr. Joshep Cronin, JOM, 65, 7, 34-49 (2001)

33. J. N. Sheth, B. Newman, B. L. Gross, JOBR, 22, 159-170 (1991)

34. C. Mathwick, N. Malhotra, E. Rigdon, JOR, 77, 39-56 (2001)

35. J. F. Petrick, JOVM, 8, 4, (2002) 332-342.

36. R. A. Westbrook, R. L. Oliver, JOCR, 18, 6, 84-91 (1991)

37. J. W. Lounsbury, J. R. Polik, LS, 14, 2, 105-119 (1992)

38. R. Oliver, AISMAM, 2, (1993) 62-85. 